\title{
Investor Timing Behavior under Imperfect Timing Information in the Factor Model
}

\author{
Sydney D. Howell \\ Manuel José da Rocha Armada
}

\section{RESUMO}

Neste trabalho, nós generalizamos um modelo de comportamento de timing, no contexto mais geral de um modelo de factores, desenvolvido por Admati et al. (1986) e mostramos que, no modelo generalizado por nós proposto, algumas afirmações universais feitas pelos autores referidos não têm validade. O modelo mais geral contém, como casos particulares, o modelo original e um modelo de mercado eficiente. O seu caso mais geral é, provávelmente, mais realista sob o ponto de vista empírico do que qualquer dos casos particulares. Algumas causas e conseqüências importantes sobre informação assimétrica não são, contudo, tratadas, quer pelo modelo generalizado quer pelo original.

Palavras-chaves: timing; selectividade; gestão de carteiras; avaliação do desempenho.

\begin{abstract}
We generalize a model of timing behavior in the factor model, developed by Admati et al. (1986) and show that, in the generalized model, some universal statements made by these authors no longer hold. The more generalized model contains, as special cases, the original model and an efficient market model. Its most general case is probably more empirically realistic than either special case. Some important causes and consequences of information asymmetry are not, however, addressed by either the original or the generalized model.
\end{abstract}

Key words: timing; selectivity; portfolio management; performance evaluation. 


\section{INTRODUCTION}

The behavior of investors with regard to selectivity and timing has attracted considerable attention, both theoretical and empirical (e.g.: Thompson, 1973; Kon and Jen, 1979; Kon, 1983; Henriksson, 1984; Chang and Lewellen, 1984; Admati et al.,1986; and Rahman, 1990).

Admati et al. (1986), gave a theorectical discussion of the factor model. They drew a conclusion, with regard to timing behavior, that "the composition of the [timing] portfolios obtained in the factor approach is independent of the quality of the private [timing] information" (Admati et al., 1986, p. 717, emphasis in original) and, equivalently, "all managers who receive only timing information shift funds among the same set of timing portfolios" (Admati et al., 1986, p. 723). They emphasise this result, because it is surprising and strongly counterintuitive one might expect that an investor who receives no timing information would not indulge in timing behavior at all, and that an investor who receives information about only a subset of the timing factors would restrict his timing decisions to the portfolios affected by that subset.

The purpose of this paper is to argue that Admati et al.'s (1986) conclusion above depends on a restrictive assumption. They assume that all investors have access to unbiased (though noisy) information about every timing factor or portfolio. It follows from standard regression arguments that all investors, in general, deal in every timing portfolio in every period. We show that, under a more general specification information quality (one which Admati et al. (1986) themselves present, but which they do not actually use in their model), the composition of the timing portfolios does indeed vary with the quality of the investor's timing information, as intuition requires.

The more generalized model, which we propose, includes as special cases both the Admati et al. (1986) model itself, in which investors deal in every portfolio in every period, and the opposite case, namely strong market efficiency (with static returns) in which private information is absent or worthless, and no investor shifts portfolios in any period. The intermediate case reflects the empirically realistic situation where investment managers are obliged, or freely choose to specialize their timing activity (or, indeed, their selectivity activity) in some subset of all the available portfolios.

We also point out that analogous conclusions to those which Admati et al. (1986) drew concerning timing behavior in their model, could also have been drawn 
concerning selectivity behavior in the same model, although Admati et al. (1986) themselves did not do so. Such statements would take the form: "all managers who receive selectivity information shift funds among the same selectivity portfolios [i.e., the entire market]". Again, empirical intuition would suggest that few managers either collect or act on asset specific information for every single asset in the market, and again our generalized model deals with the implausibility.

Some challenging problems remain for future research, which neither the original nor the generalized model are disigned to address.

The structure of this paper is that section 1 states and analyses Admati et al.'s (1986) most general concept of timing information; section 2 shows that Admati et al. (1986) actually use only a special case of this timing information in their model of investor timing behavior. Section 3 generalizes Admati et al.'s (1986) model of investor behavior to include their own most general definition of timing information. This generalized model confirms that timing behavior is indeed dependent on the quality of timing information, if the latter is given Admati et al.'s (1986) broadest definition. Section 4 compares the two model structures in terms of their empirical realism and their theorectical completeness. Section 5 summarizes and makes suggestions for further research.

\section{Admati et al.'s (1986) Concept of Timing Information AND Measures of Information Quality}

Admati et al. (1986) assume that the next true state of returns for (say) K portfolios (or factors or assets) is the ( $\mathrm{Kx} \mathrm{l})$ vector $\mathrm{R}$ (in the notation of Admati et al., 1986, p. 721). The investor receives information about the true returns in the form of a signal $\mathrm{Y}$, which is a function $\mathrm{Y}(\mathrm{R})$ of their true state. Clearly, for perfect timing information, Y must be the Identity. Admati et al. (1986) suggest on page 721 , that the signal function takes the form:

$$
Y(R)=C R+\eta
$$

where:

$\mathrm{C}$ is some $(\mathrm{KxK})$ matrix and

$\eta(\mathrm{Kx} 1)$ is a normally distributed noise term, with mean zero and variance-covariance matrix $\Sigma(\mathrm{KxK})$. 
It is useful to specify $\mathrm{C}$ as a symmetric matrix and to distinguish four potential states of $\mathrm{C}$ and $\Sigma$ :

a) perfect information occurs where $\mathrm{C}=\mathrm{I}(\mathrm{KxK})$ and $\Sigma$ is a $(\mathrm{KxK})$ null matrix (rank zero). Under these assumptions $\eta$ is identically zero, so:

$$
Y(R)=I R=R
$$

$\mathrm{C}$ need not, in general, be the Identity, provided it is of full rank. If $\mathrm{C}$ is known and of full rank, the investor can recover $\mathrm{R}$ by applying the inverse transformation to $\mathrm{Y}$ :

$C^{-1} Y(R)=C^{-1} \quad C R=R$

b) worthless information can arise in many cases, of which the most tractable and relevant is where $\mathrm{C}$ is a null matrix $(\mathrm{KxK})$. Under this assumption $\mathrm{Y}(\mathrm{R})$ reduces to:

$$
Y(R)=0 \times R+\eta=\eta
$$

so that the signal is pure noise and should be ignored by the rational investor, under any specification of $\Sigma$.

There are two interesting cases of imperfect information:

c) imperfect information, case one: the rank of $\mathrm{C}(\mathrm{KxK})$ is less than $\mathrm{K}$ and $\Sigma$ is any positive semidefinite matrix $(\mathrm{KxK})$ with a rank in the range 1 to $\mathrm{K}$ :

$$
Y(R)=C R+\eta
$$

In this case, some information about $\mathrm{R}$ is irretrievably lost by $\mathrm{C}$. An extreme example is an investor who collects private information only on factor i. This 
gives a $\mathrm{C}$ matrix of rank one, in which $\mathrm{C}_{\mathrm{ii}}$ is one and all other elements are identically zero (kronecker delta). In general, as we show in (22) below, for the null space of $\mathrm{C}$ (i.e., for any portfolios for which the investor receives no useful signal), the investor should not act on the signal, and the quality of the noise element with respect to the null space of $C$ is irrelevant. The case where $C$ and $\Sigma$ have the same rank $\mathrm{L}<\mathrm{K}$, and the same null space, is one where the investor receives no signal at all for the portfolio(s) or factor(s) in the shared null space.

In this case c), the quality of the investor's information varies with both $\mathrm{C}$ and $\Sigma$, in a potentially complex way. A unit reduction in the rank of $\mathrm{C}$ deprives the investor of information about one weighted combination of the factors (the simplest such combination is one which puts $100 \%$ weight on a single factor or portfolio). In the limit, if the rank of $\mathrm{C}$ falls to zero, the signal is the worthless signal of case b). Information about any subspace of the factors which is not suppressed by $\mathrm{C}$ can, in principle, be recovered from CR by the use of an appropriate generalized inverse of C (Press, 1972).

In general, the rank (or the span) of $\Sigma$ has an opposite significance: if the rank of $\Sigma$ falls by one, there is a subspace (weighted combination) of the $\mathrm{K}$ factors which is no longer affected by random error. Even one such subspace could eventually make the investor very rich, if it is also spanned by $\mathrm{C}$, since the investor would enjoy perfect timing information about it. If so, any residual imperfection in the investor's timing information would be of academic interest rather than economic. If the rank of $\Sigma$ is reduced to the limit of zero, there is no longer any random error in the signal $\mathrm{Y}$, as in case a), though the rank of $\mathrm{C}$ will determine whether any subspace enjoys information at all. The economic value of the signal is therefore not measurable by the rank of $\mathrm{C}$ alone, or by either the rank or the magnitudes of $\Sigma$ alone: an investor could become rich without limit if the rank of $\mathrm{C}$ is as low as one, provided that the core of $\mathrm{C}$ coincides with the null space of a $\Sigma$ of rank between zero and (K-1).

d) imperfect information, case two: $\mathrm{C}=\mathrm{I}$ (the Identity $\mathrm{KxK}$ ) and $\Sigma$ is a positive definite matrix (KxK).

In this case:

$$
Y(R)=I R+\eta=R+\eta
$$

This is a rather special situation. As in a), but not in $b$ ) or $c$ ), the signal contains full rank information about all the elements of $\mathrm{R}$, and this information is unbiased, 
since only random noise $\eta$ is added. As we discuss below, a regression of $\mathrm{R}$ on the signal $\mathrm{Y}$ will place a non zero weight on all the elements of $\mathrm{Y}$, and the rational investor with finite risk tolerance will therefore, in general, make a non zero response to this regression (ignoring transaction costs).

Clearly, in case d), the quality of the signal information is a function of $\Sigma$ alone and, in practice, it is inversely related to some measure of the size of the elements of $\Sigma$. It does not seem practically relevant, in case d), to model variations in information quality by variations in the rank of sigma, because if this rank falls below $\mathrm{K}$, the investor has perfect information about the next movement of some subspace of the assets, with the results already discussed.

Cases a), b) and d) above, are special cases of c) and, of course, more general formats than c) can be devised. The model of the information signal in (1) is sufficiently general to be used to model either timing or selectivity signals, or their combination. Case c) can be used to model a situation which we think is empirically common, namely where investment managers specialise mainly as either market timers or stock pickers and, in both cases, either choose, or are instructed, to deal in only a subset of the available assets or portfolios.

Having considered Admati et al.'s (1986) general model of information structure and quality, we now look at their actual model of investor decision behavior.

\section{The Structure of the Admati et al. (1986) Model}

Admati et al. (1986) built a one period model, in which the returns to $\mathrm{N}$ assets are driven by the effects of $\mathrm{K}$ shared factors $(\mathrm{KxN})$, plus $\mathrm{N}$ idiosyncratic disturbance terms, one for each asset. The true state of the $\mathrm{K}$ factors, the vector $\delta_{\mathrm{t}}(\mathrm{Kxl})$, produces a change in the returns of the $\mathrm{N}$ assets via the matrix $\mathrm{B}(\mathrm{NxK})$, in the form of a return component $\mathrm{B} \delta_{t}(\mathrm{Nx} 1)$. Both the $\mathrm{K}$ factors and the $\mathrm{N}$ asset specific movements are normally distributed, having variance-covariance matrices respectively of I (Identity $\mathrm{KxK}$ ) and $\mathrm{D}(\mathrm{NxN})$, and these are independent of each other. $\mathrm{D}$, in practice, is expected to be close to diagonal, since the factor structure presumably accounts for all or most of the correlations between assets (i.e., the factor structure) may itself be factored in a form $\mathrm{BB}^{\prime}(\mathrm{NxK}) \times(\mathrm{KxN})$, such that the covariances between the factors themselves may be taken as the identity I $(\mathrm{KxK})$ without loss of generality.

Investors in the Admati et al. (1986) model receive timing information with respect to time period $t$ in the form of a timing signal $\mathrm{Y}_{t}^{\mathrm{T}}(\mathrm{Kx} 1)$ which is a 
function $Y_{t}^{\mathrm{T}}\left(\delta_{t}\right)$ of the true changes $\delta_{t}$ of the $\mathrm{K}$ factors. Investors also receive selectivity information in the form of a selectivity signal $Y_{t}^{S}$. This $(\mathrm{Nxl})$ vector is a function $\mathrm{Y}_{\mathrm{t}}^{\mathrm{S}}\left(\varepsilon_{\mathrm{t}}\right)$ of the $(\mathrm{Nxl})$ vector $\varepsilon_{\mathrm{t}}$ of the true values of asset specific disturbances.

On examination, the signal functions $\mathrm{Y}_{t}^{\mathrm{T}}$ and $\mathrm{Y}_{\mathrm{t}}^{\mathrm{S}}$ are seen to be examples of case d) in section 1 above, in which matrix $\mathrm{C}$ is the identity. For the timing signal:

$$
Y_{t}^{T}\left(\delta_{t}\right)=\delta_{t}+\eta_{t}
$$

where:

$\eta_{\mathrm{t}}(\mathrm{Kxl})$ is a normally distributed noise term with mean zero and variance-covariance matrix $\Sigma(\mathrm{KxK})$. This means that the function $\mathrm{Y}_{\mathrm{t}}^{\mathrm{T}}$ consists of an accurate report $\delta_{t}(\mathrm{Kx} l)$ of the true state of every single factor, plus unbiased random noise. Hence, under standard regression assumptions discussed below (assuming finite constant risk aversion), all investors who receive such a signal will make a non zero change in their investments in response to every non zero element of $Y_{t}^{\mathrm{T}}$ (i.e., they will, in general, use the full set of factor timing portfolios, as Admati et al. (1986) state, and indeed in every period, since transaction costs are ignored). Similarly, for the selectivity signal Admati et al. (1986) use:

$$
Y_{t}^{S}\left(\varepsilon_{t}\right)=\varepsilon_{t}+\theta_{t}
$$

where:

$\varepsilon_{\mathrm{t}}(\mathrm{Nxl})$ is the true future idiosyncratic return to every asset $\mathrm{t}$ and $\theta_{\mathrm{t}}(\mathrm{Nxl})$ is a noise term with mean zero and variance-covariance matrix $\Omega(\mathrm{NxN})$.

This embodies the similar (but empirically much more startling) assumption that the investor receives an unbiased signal $\varepsilon_{\mathrm{t}}(\mathrm{N} \times \mathrm{l})$ of the true idiosyncratic return to every single asset in the market, together with unbiased random noise $\theta_{\mathrm{t}}$. Again, under standard regression assumptions, the signal contains usable information about every single asset and, so, the rational investor takes asset selectivity decisions in the entire space of assets, i.e., the investor will, in general, buy or sell non zero quantities of every single asset in every period, in response to $\mathrm{Y}_{\mathrm{t}}^{\mathrm{S}}$, in addition to the movements of all or most assets implied by the factor signal $\mathrm{Y}_{\mathrm{t}}^{\mathrm{T}}$. 
Admati et al. (1986) impose the restriction that $\Sigma$ is of full rank K and $\Omega$ is of full rank $\mathrm{N}$ (I is the identity and, so, has full rank K). These restrictions are needed in order to ensure a finite solution of (12) below and are equivalent to an assumption that there is no subspace of assets about which the investor receives perfect timing information or perfect selectivity information.

Admati et al. (1986) use a standard model of utility maximisation. Investors are assumed to have positive utility identical to the expected payoff of the portfolio and negative utility which is a linear multiple of the variance of the portfolio (i.e., constant absolute risk tolerance $\rho$ ). Under the stated assumptions, the utility function is maximized, given the signals $\mathrm{Y}_{\mathrm{t}}^{\mathrm{T}}$ and $\mathrm{Y}_{\mathrm{t}}^{\mathrm{S}}$, by the following optimal portfolio $\alpha^{*}$ (for a fuller explanation of the notation see appendix):

$$
\alpha^{*}\left(Y_{t}^{T}, Y_{t}^{S}\right)=\rho\left(\operatorname{Var}\left(R_{t} \mid Y_{t}^{T}, Y_{t}^{S}\right)\right)^{-1} E\left(R_{t} \mid Y_{t}^{T}, Y_{t}^{S}\right)-R_{o} e
$$

The elements needed for the above optimal portfolio calculation are derived by Admati et al. (1986) using standard regression methods:

$$
\begin{aligned}
& E\left(R_{t} \mid \mathrm{Y}_{\mathrm{t}}^{\mathrm{T}}, \mathrm{Y}_{\mathrm{t}}^{\mathrm{S}}\right)=\hat{E}+B(I+\Sigma)^{-1}\left(\delta_{t}+\eta_{t}\right)+(D+\Omega)^{-1} D\left(\varepsilon_{t}+\theta_{t}\right) \\
& \operatorname{Var}\left(R_{t} \mathrm{Y}_{\mathrm{t}}^{\mathrm{T}}, \mathrm{Y}_{\mathrm{t}}^{\mathrm{S}}\right)=B\left(I+\Sigma^{-1}\right)^{-1} B^{\prime}+\left(D^{-1}+\Omega^{-1}\right)^{-1}
\end{aligned}
$$

By substituting (10) and (11) into (9) Admati et al. (1986) derive the optimal portfolio itself:

$$
\rho\left(B\left(I+\Sigma^{-l}\right)^{-1} B^{\prime}+\left(D^{-l}+\Omega^{-1}\right)^{-l}\right)^{-1}\left(E+B(I+\Sigma)^{-l}\left(\delta_{t}+\eta_{t}\right)+(D+\Omega)^{-l} \mathrm{D}\left(\varepsilon_{\mathrm{t}}+\theta_{\mathrm{t}}\right)\right.
$$

Admati et al. (1986) next consider an imaginary investor who receives timing information only (the assumption that the selectivity signal is worthless or absent is an example of case b) of section 1 above). For such an investor the optimal portfolio simplifies to: 


$$
\alpha^{*}\left(\mathrm{Y}_{\mathrm{t}}^{\mathrm{T}}\right)=\rho\left(B\left(I+\Sigma^{-1}\right)^{-1} B^{\prime}+D\right)^{-1}\left(E+B(I+\Sigma)^{-1}\left(\boldsymbol{\delta}_{t}+\eta_{t}\right)\right)
$$

Within (13), the expression that decides its span, assuming that $\mathrm{E}$ and $\delta_{t}$ contain no fixed zeros, is:

$$
\left(B\left(I+\Sigma^{-1}\right)^{-1} B^{\prime}+D\right)^{-1} B(I+\Sigma)^{-1}
$$

More generally, for an investor who receives both timing and selectivity signals, as specified, the expression that decides the span of the timing decision in (12) is:

$$
\left(B\left(I+\Sigma^{-1}\right)^{-1} B^{\prime}+\left(D^{-1}+\Omega^{-1}\right)^{-1}\right)^{-1} B(I+\Sigma)^{-1}
$$

Admati et al. (1986) correctly state that in expression (13) or (15) the span of the timing decisions is the whole space of timing portfolios, of dimension $\mathrm{K}$, and does not depend on the noise/information matrix $\Sigma$ (in fact, this span cannot depend on any property of $\Sigma$ other than its rank and the rank of $\Sigma$ is fixed at $\mathrm{K}$ as already discussed).

Admati et al.'s (1986) conclusions, as stated at the start of this paper, follow naturally from (9) to (15), along with a more startling corollary, not mentioned by Admati et al. (1986), with regard to selectivity behavior, namely that all investors, whatever the quality of their selectivity information, shift assets among the same set of selectivity portfolios (i.e., all investors, in general, buy and sell all assets, in every period, on a selectivity basis).

We argue that these conclusions follow from Admati et al.'s (1986) assumption that all investors receive a very generous information set, namely case d) of section 1. In the next section, we show that if one assumes the broader information structure of case c) of section 1, as postulated by Admati et al. (1986), and repeats their modelling method, the Admati et al. (1986) generalisations do not hold. 


\section{Investor Utility Maximisation under a more General Model of IMPERFECT TIMING INFORMATION}

For simplicity we imitate Admati et al. (1986) in modelling the investor who receives only timing information, as in (13) and (14) above. The method generalizes immediately to deal with selectivity information.

Using the general signal specification of (1), we have:

$$
Y_{t}^{T}\left(\delta_{t}\right)=C \delta_{t}+\eta_{t}
$$

Given that $\delta_{\mathrm{t}}$ and $\eta_{\mathrm{t}}$ have variance-covariances $\mathrm{I}(\mathrm{KxK})$ and $\Sigma(\mathrm{KxK})$ respectively, and are uncorrelated, the variance-covariance matrix for the true factor state $\delta_{\mathrm{t}}$ and the factor signal $\mathrm{Y}_{\mathrm{t}}^{\mathrm{T}}\left(\delta_{\mathrm{t}}\right)$ of $(16)$ is $(2 \mathrm{~K} \times 2 \mathrm{~K})$ :

$$
\left[\begin{array}{cc}
I & C^{\prime} \\
C & C C^{\prime}+\Sigma
\end{array}\right]
$$

Hence, by regression of the true factor state $(\mathrm{Kxl})$ on the timing signal $(\mathrm{Kxl})$, we obtain the expectation of true returns to the $\mathrm{N}$ assets, $\mathrm{R}_{\mathrm{t}}$, conditional on the signal $\mathrm{Y}_{\mathrm{t}}^{\mathrm{T}}$ :

$$
E\left(R_{t} \mid \mathrm{Y}_{\mathrm{t}}^{\mathrm{T}}\right)=\hat{E}+B C^{\prime}\left(C C^{\prime}+\Sigma\right)^{-1} \mathrm{Y}_{\mathrm{t}}^{\mathrm{T}}
$$

and:

$$
\operatorname{Var}\left(R_{t} \mid \mathrm{Y}_{\mathrm{t}}^{\mathrm{T}}\right)=B\left(I-C^{\prime}\left(C C^{\prime}+\Sigma\right)^{-1} C\right) B^{\prime}+D
$$

The optimal portfolio for the investor receiving the signal (16) is, by substituting (18) and (19) in (9): 


$$
\alpha^{*}\left(\mathrm{Y}_{\mathrm{t}}^{\mathrm{T}}\right)=\rho\left(B\left(I-C^{\prime}\left(C C^{\prime}+\Sigma\right)^{-1} C\right) B^{\prime}+D\right)^{-1}\left(E+B C^{\prime}\left(C C^{\prime}+\Sigma\right)^{-1}\left(C \delta_{t}+\eta_{t}\right)\right)
$$

This model is fairly general. For $\mathrm{C}=\mathrm{I}$ (Identity matrix of rank $\mathrm{K}$ ) it is equivalent to the Admati et al.'s (1986) model of (12). For C $=0$ (i.e., the null matrix (KxK) of rank zero), it reduces to the assumptions of strong market efficiency, where there is no useful private timing information. In such case, the investor holds unchanged the optimum portfolio under uncertainty, namely:

$$
\alpha^{*}=\rho\left(B B^{\prime}+D\right)^{-1} E
$$

In general, matrix $\mathrm{C}$ may take any rank from zero to $\mathrm{K}$, and the inverse $\left(\mathrm{CC}^{\prime}+\right.$ $\Sigma)^{-1}$ which occurs twice in (20) will always exist, given the assumption that $\Sigma$ is of full rank K. Hence, (20) can always be solved for an optimal response to the timing signal, whatever the rank of $\mathrm{C}$. The expression determining the rank of (20) and, hence, the span of the timing portfolios, is in this model:

$$
B C^{\prime}\left(C C^{\prime}+\Sigma\right)^{-1}\left(C \delta_{t}+\eta_{t}\right)
$$

The rank of (22) is, clearly, constrained to be the lower of rank (B), which is by assumption $\mathrm{K}$, and rank ( $\left.\mathrm{C}^{\prime}\right)$, say $\mathrm{M}$, where (21) shows the consequences of the special case $\mathrm{M}=0$. Hence, each investor takes timing decisions in some $\mathrm{M}$ dimensional subspace of the $\mathrm{K}$ timing portfolios and not, necessarily, the whole $\mathrm{K}$ dimensional space. Under these assumptions (which, in our view, are empirically realistic) Admati et al's. (1986) general statements do not hold.

Note that the signal $\mathrm{C} \delta_{\mathrm{t}}+\eta_{\mathrm{t}}$ still varies with full rank $\mathrm{K}$, whatever the rank of $\mathrm{C}$, because $\mathrm{K}$ is the assumed rank of $\Sigma$, the variance of the noise element $\eta_{\mathrm{t}}$ in the signal. However, any variations of $\eta_{\mathrm{t}}$ in the null space of $\mathrm{C}$ can be ignored by the investor, according to (22).

Exactly similar methods (ommited here) can be used to model the case of an investment manager who acts on selectivity information for only a subset of assets. Similar conclusions follow, that the selectivity portfolio depends on the quality of the selectivity information. 


\section{Empirical Realism}

Our generalization of the Admati et al. (1986) model avoids an assumption which we think empirically unrealistic, namely that any investors at all receive, and react to, unbiased private information about every source of asset movement in every period. Our generalized model also requires certain assumptions, but we argue that these are not empirically unrealistic, within this general class of model.

For example, in order that the inverses needed in (20) should exist, D and $\Sigma$ must have full rank ( $\mathrm{N}$ and $\mathrm{K}$ respectively). The first constraint is merely that no two assets are completely dependent. As Admati et al. (1986) point out, this is not restrictive, and can be used as a test for the number $\mathrm{N}$ of genuinely independent assets needing to be modelled (similar logic applies to determining $\mathrm{K}$, the number of factors).

The restriction that $\Sigma$ must be of full rank K for every investor means that each investor must have access to a noise signal (a worthless forecast) about every factor. This is not empirically unrealistic. If we can assume semi-strong market efficiency, the whole of published investment analysis and journalism approximates to such a signal, which is available to all investors. Furthermore, the generalized model, unlike the Admati et al. (1986) original, does not require that investors should actually react to the whole of this signal: for portfolios in the null space of $\mathrm{C}$ (portfolios in which the investor has been instructed not to deal, or has decided not to deal, perhaps because of unwillingness or inability to collect information) according to (22) the signal can be ignored entirely.

Exactly similar considerations apply if we extend the generalized model to deal with selectivity information, i.e., to the level of $\mathrm{N}$ individual assets. In this case, the asset specific noise signal $\theta$ is required to be of full rank $\mathrm{N}$, which means that every investor must have access to a worthless random forecast for all $\mathrm{N}$ assets, having the covariance matrix $\Omega$. Again, under semi-strong market efficiency, financial journalism supplies such a signal, and the generalized model again does not require that all investors react to all of the signal, or even consider it at all.

\section{Suggestions for Future Research}

In the generalized model, the universal statements cited from Admati et al. (1986) at the beginning of this paper, are no longer true. However, some interesting questions are not addressed by either the original or the generalized model. One 
example is the possible dynamics of investor learning, if we relax the assumptions that the true generating models for returns and signals are static and known to investors. A much more fundamental question is the role of information asymmetry as an aspect of market equilibrium. It seems desirable in future to model both the causes and the consequences of information asymmetry.

Admati et al. (1986) do not explicitly discuss the causes or consequences of asymmetry among investors. In their model, investors may vary in their market timing information (noise) measures $\Sigma$, or their asset specific information (noise) measures $\Omega$, and their risk tolerance $\rho$ and, clearly, unless some asymmetry exists, the information signals cannot be considered as private at all, and there would almost certainly be unwanted results in a market clearing context. The very fact that all investors in the Admati et al. (1986) model receive an unbiased and, hence, informative signal about every asset (even if all investors suffer diverse noise variances $\Sigma$ and $\Omega$ ) is possibly a difficulty, and Admati et al. (1986, p. 729) point out that although their assumptions are consistent with most of the empirical literature, they "have not been justified by a theorectical intertemporal asset pricing model which, explicitly, admits asymmetric information". Our generalized model adds a potential diversity in $\mathrm{C}$ to the original model's potential diversity in $\Sigma, \Omega$ and $\rho$, but neither the Admati et al. (1986) original not the generalization explains why such diversity should exist, and what are its consequences for market clearing.

Intuition suggests that any investor could, in principle at least, seek for private information about any asset (this far from Admati et al.'s (1986) demanding requirement that every investor should receive, and act on, information about every asset). If this is so, an optimizing theory (as opposed to an empirical description) should treat $\Sigma$ and/or $\mathrm{C}$ not as givens, but as decisions taken by individual agents, on the basis of such factors as their risk aversion, personal costs and opportunities of collecting information etc. Of course, there would be litle conceptual problem in including costless insider information, if it is decided to admit this to the model, and in such a case even insiders will be relatively underinformed about assets for which they are not insiders, which may be most of the market.

On moving from the level of optimal decisions by individuals to the market clearing level, it seems likely that the value of information, and the overall levels of asymmetry, both in information and returns, would all need to be jointly determined in an equilibrium model, and this might have interesting implications. We suspect that if an equilibrium theory of financial markets, under costly and (potentially) asymmetric information, could be fully developed, it would yield some important insights, some of which might be as counterintuitive as those of efficient market theory. 


\section{APPENDIX}

Summary of notation used from Admati et al. (1986):

$\mathrm{Y}_{\mathrm{t}}^{\mathrm{T}} \quad$ Timing signal $(\mathrm{Kxl})$;

$\mathrm{Y}_{\mathrm{t}}^{\mathrm{S}} \quad$ Selectivity signal $(\mathrm{Nxl})$;

$\alpha^{*}\left(Y_{t}^{T}, Y_{t}^{S}\right) \quad$ Optimal portfolio given timing and selectivity signals (nxl);

$\rho \quad$ Risk tolerance (scalar);

$\mathrm{R}_{\mathrm{t}} \quad$ Returns of the $\mathrm{N}$ assets in the market at time $\mathrm{t}(\mathrm{Nxl})$;

$\mathrm{R}_{0} \quad$ Risk free return (scalar);

e Nxl vector of ones;

$\hat{\mathrm{E}} \quad$ Expected returns of all $\mathrm{N}$ assets in the market $(\mathrm{Nxl})$;

E Expected excess returns of $\mathrm{N}$ assets in the market $(\mathrm{Nxl})$;

B NxK matrix: impacts of $\mathrm{K}$ factors on $\mathrm{N}$ risky asset returns;

$\Sigma \quad$ KxK variance of noise $\eta_{\mathrm{t}}$ element in timing signals;

$\delta_{\mathrm{t}} \quad \mathrm{Kxl}$ vector of timing signals (true values);

$\eta_{\mathrm{t}} \quad \mathrm{Kxl}$ vector of noise element in timing signals;

D NxN variance of returns to $\mathrm{N}$ risky assets before signals;

$\Omega \quad$ NxN variance of the noise $\theta_{\mathrm{t}}$ in selectivity signals;

$\varepsilon_{\mathrm{t}} \quad$ Nxl vector of selectivity signals (true values);

$\theta_{t} \quad$ Nxl vector of noise element in selectivity signals. 


\section{RefERENCES}

ADMATI, A. R. et al.

On timing and selectivity. The Journal of Finance, v. 16, n. 3, p. 715-732, July 1986.

CHANG, E. C;

LEWELLEN,W. G.

Market timing and mutual fund investment performance. The Journal of Business, v. 57, n. 1, p. 57-72, Jan. 1984.

HENRIKSSON, R. D.

Market timing and mutual fund performance : an empirical evaluation. The Journal of Business, v. 57, n. 1, p. 73-96, Jan. 1984.

KON, S. J.

The market-timing performance of mutual funds managers. The Journal of Business, v. 56, n. 3, p. 323-347, 1983.
KON, S. J.

JEN, F. C.

The investment performance of mutual funds : an empirical investigation of timing, selectivity and market efficiency. The Journal of Business, v. 52 , n. 2, p. 263-289, Apr. 1979.

PRESS, S. J.

Applied multivariate analysis. In: WINKLER, R. L. Quantitative methods for decision making. New York : Holt, Rinehart and Winston, 1972.

THOMPSON, R.

The effects of the optimal utilization of market forecasts on mutual fund performance in the period : 1960-1969. Graduate School of Business - University of Rochester, 1973. (working paper). 